ORIGINAL ARTICLE

\title{
Bacterial Contamination of Healthcare Workers' Mobile Phones in Pediatric and Neonatal Departments of Two Hospitals in Zagazig City
}

\author{
Tarek Abd El-Rahman Attia ${ }^{1}$, Osama Taha Amer ${ }^{2}$, Ahmed Mohamed Morad Asaad ${ }^{3}$, \\ Mohamed Eid Bakry Mohamed ${ }^{4}$
}

1 Faculty of Medicine, Zagazig University, Department of Pediatrics, Sharkia Egypt

2 Faculty of Medicine, Zagazig University, Department of Pediatrics, Sharkia Egypt

3 Faculty of Medicine, Zagazig University, Department of Medical Microbiology \& Immunology, Sharkia Egypt

4 Faculty of Medicine, Zagazig University, Department of Pediatrics, Sharkia Egypt

Corresponding author

Name : Mohamed Eid

Bakry Mohamed

Tel. $\quad$ : 01009718022

E.mail

Mohamed.bakry75.mb@gmail.com

Current job : Resident

pediatrician at el-mabara hospital

$\begin{array}{ll}\text { Submit Date } & \text { 2019-06-22 } \\ \text { Revise Date } & \text { 2019-08-04 } \\ \text { Accept Date } & \text { 2019-08-24 }\end{array}$

\section{INTRODUCTION}

$\mathrm{N}$ osocomial infections NIs are one of the leading causes of mortality and morbidity in NICUs and PICUs. The
Introduction: Nosocomial infections NIs are one of the leading causes of mortality and morbidity in neonatal intensive care units NICUs and pediatric intensive care units PICUs. The incidence of infections varies widely among NICUs (7-25.5\%), and (18-30\%) among PICUs depending on environmental factors and differences in clinical practice (Brito et al., 2010).

Objective: To investigate the prevalence of bacterial contamination of mobile phones of HCWs in pediatric departments (ward, NICU and PICU) of Zagazig University Hospital and Al-Mabarrah General Hospital, and characterize their antibiotic sensitivity patterns. Besides, this study aimed to identify the possible potential risk factors for acquisition of colonizing or pathogenic bacteria on HCWs mobile phones, and assess the attitude of HCWs towards mobile phone use during their clinical practice.

Methods: This is a prospective cross sectional study, This study included 350 health care workers (HCWs). Questionaire was distributed through the selected HCWs. Bacterial isolation from swabs from cell phones of HCWs was conducted according to standard bacteriology methods.

Results: The most common organism isolated was S.epidermidis (72.8\%), followed by S.aureus (16.7\%), Bacillus spp.(6.2\%) and E.coli (3.1\%).There was statistaclly significant association between the bacterial culture results with HCWs acceptance to restrict mobile use inside hospitals $\left(\mathrm{p}=0.038^{*}\right)$, using phones inside toilets $\left(\mathrm{p}=0.038^{*}\right)$, and keeping phones in the uniform pocket $\left(\mathrm{p}=0.00^{*}\right)$.

Conclusion: Use mobile phones by HCWs during the work in the NICUs and PICUs carry ahigh risk for the NIs, Regular cleaning of the phones is recommended to decrease the contamination rate.

Key words; Bloodstream infection, C-reactive protein, Cerebrospinal fluid, Community-associated methicillin resistant Staph aureus, Gastrointestinal tract, Health-care associated infections 
According to United State department of health and human services centers for diseases prevention and control, nosocomial infections are defined as all patients who are neither infected nor are in incubation period at the time of admission and have positive culture after 48 hours of admission ${ }^{[2]}$.

Neonatal deaths account for over a third of the global burden of child mortality. In many developing countries neonatal mortality rates are as high as $40-50$ per 1000 live births,. Unfortunately, hospitals in developing countries are at high risk of infection transmission, and improvements in neonatal outcomes are subverted by hospital-acquired infections and their associated morbidity, mortality and cost. These infections can be attributed to lack of knowledge and training about basic infection control processes, coupled with inadequate infrastructure, systems of care and resources. This has serious consequences when devices such as intravenous catheters and ventilators are introduced without sufficient attention to the substantial risk of infection they entail ${ }^{[4]}$.

Nosocomial Infections are one of the most important problems in all hospitals. accelerated improvements in diagnostic and therapeutic methods have helped significant progress in clinical medicine but with plentiful using of invasive technologies, fatal nosocomial infections cause many damages every day ${ }^{[3]}$. The occurrence of NIs differs in different patient populations and different hospitals. The pediatric patient population especially faces an increased risk of NIs. Many studies worldwide have been performed to identify the epidemiology of NIs among pediatric patients. Bloodstream infection (BSI) and pneumonia are the most common NI in children ${ }^{[5,6]}$. Healthcare workers' (HCWs) hands are the most common vehicle for the transmission of healthcare-associated pathogens from patient to patient and within the healthcare environment ${ }^{[7]}$.

In an attempt to provide better communication and health care facilities, nowadays nearly $100 \%$ of HCWs own and use mobile phones. In fact, uncontrolled use of mobile phones by HCWs increases the spread of nosocomial infections. Actually, not all $\mathrm{HCW}$ s clean their hands before or after using their phones which exposes both themselves as well as the others to the risk of transferring infections. HCWs can transfer microorganisms from the patient to himself or from one of the samples taken from him to their own hands, from their hands to their phones, and from their phones to their faces, mouths and ears. In reverse, HCW scan transfer microorganisms from their phones to patients or to other members of the community outside the health care facility ${ }^{[8]}$.

Objective: To investigate the prevalence of bacterial contamination of mobile phones of HCWs in pediatric departments (ward, NICU and PICU) of Zagazig University Hospital and Al-Mabarrah General Hospital. To characterize a baseline of data on types of bacterial isolates and their antibiotic sensitivity patterns. To identify any potential risk factors for acquisition of colonizing or pathogenic bacteria on HCWs mobile phones. To explore the attitude of HCWs towards mobile phone use.

\section{AIM OF THE WORK}

To investigate the prevalence of bacterial contamination of mobile phones of HCWs in pediatric departments (ward, NICU and PICU) of Zagazig University Hospital and AlMabarrah General Hospital, also to characterize a baseline of data on types of bacterial isolates and their antibiotic sensitivity patterns, and to identify any potential risk factors for bacterial colonization, as well as the presence of pathogenic bacteria on HCWs' mobile phones.

\section{PATIENTS AND METHODS}

Site of the study:

The study was conducted at Microbiology and Immunology Department of Zagazig University Hospital in the period from April 2018 to october 2018. This prospective cross sectional study was approved by The Research Committee of Faculty of Medicine. The study was conducted according to the guidelines of Helsiniki Declaration, written informed consent was obtained from all participants.

Inclusion criteria: All HCWs in Pediatric Departments of ZUHs and Al Mabarra 
General Hospital, including clinicians, nurses and technicians.

Type of study: A cross-sectional study was conducted according to the international guidelines of Strengthening the Reporting for Observational Studies in Epidemiology; STROBE (STROBE Checklists, 2014).

Sample size: All healthcare worker's personels at NCUs and PICUs in ZUHs and Al Mabarra hospital were included in the study which equall 350 .

\section{- Questionnaire interview}

A well-constructed standardized selfadministered questionnaire was distributed as hard copies for all participants. Interviews were performed in each hospital with all HCWs to explain the purpose of the study and to give instructions for the questionnaire to be filled anonymously. The questionnaire was initially designed in English, and translated into Arabic by an expert of biostatistics to fit with local colloquial Arabic terminology used by physicians and health educators in our community. After translation and back translation, a panel of experts was asked to assess the preliminary questions and provide structured comments with respect to face and content validity, comprehensibility and comprehensiveness.

The questionnaire was applied on 350 HCWs including pediatricians, nurses and technicians, while participants were filling the questionnaire, swabs were taken from their mobile phones for bacteriological investigations.

The questionnaire was composed of three components to address the knowledge and attitude of HCWs regarding their use of mobile phones during work times in hospitals as well as to assess and compare the practice of hand hygiene and practice of cell phone hygiene among HCWs in both hospitals. The first component was used to collect data on the participant's demographics, including age, gender, profession, seniority, and years of experience. The second part was includes questions regarding the use of mobile phones at work, , frequency of mobile phone use, model of mobile phone, presence of a cover and HCWs' perception of the potential role of their mobile phones in spreading infections in hospital settings.

The third component of the questionnaire included questions on mobile phone hygiene practices; including the frequency of mobile phone disinfection and the disinfectant which clinicians used to clean their mobiles.

\section{- Bacteriological investigations}

Samples were obtained from cell phones of all participants using sterile cotton swabs. Prior to sample collection, swabs were moistened in sterile water and will be rotated over the front screen and the back of the cell phones. All swabs were immediately inoculated into Amies transport media and processed within one hour in the laboratory of Microbiology and Immunology Department, Faculty of Medicine, Zagazig University. Swabs were inoculated into blood and Mac Conkey agar plates, and incubated aerobically at $37^{\circ} \mathrm{C}$ for 24 hours.

Isolated bacterial agents were identified according to the standard microbiological methods described by Murray et al (2003) ${ }^{[9]}$.. All suspected colonies were identified using Gram staining technique, carbohydrate fermentation tests and biochemical tests such as catalase and coagulase for Gram-positive cocci, and oxidase, urease, $\mathrm{H} 2 \mathrm{~S}$ production, citrate utilization, nitrate reduction, indole and others for identification of Gram-negative bacilli.

Quantification of bacterial growth on all plates were performed using the semiquantitative colony-forming unit (CFU) count method in which the number of colonies isolated from each mobile phone will be divided by the area sampled and recorded as $\mathrm{CFU} / \mathrm{ml}$.

They were identified using Gram's staining, colony morphology and appropriate biochemical tests. For identification of Grampositive Cocci(GPC); isolates that appeared as medium sized circular, white or golden yellow with smooth convex surface and entire edge and were $\beta$-hemolytic or non-hemolytic on blood agar plates and were positive for catalase, slide and tube coagulase and Voges Proskauer tests were considered as Staphylococcus aureus (S. aureus). Nonhaemolytic, catalase-positive, coagulase- 
negative, bacitracin-sensitive GPC were identified as Micrococcus spp., while catalase positive, coagulase-negative and bacitracinresistant GPC were considered as coagulasenegative staphylococci (CoNS). S.aureus and CoNS identified isolates were further checked for their susceptibility to methicillin using oxacillin $(1 \mu \mathrm{g})$ and cefoxitin $(30 \mu \mathrm{g})$ discs on Mueller Hinton agar plates supplemented by $4 \% \mathrm{NaCl}$ by disk diffusion method described by modified Kirby-Bauer ${ }^{[10]}$ according to the guidelines of Clinical Laboratory Standards Institute. Vancomycin susceptability testing was perrformed using the E-test method with an inoculum of 0.5 McFarland turbidity standard according to CLSI guidelines ${ }^{[10]}$. S. aureus ATCC 29213, Escherichia coli ATCC 25921 and P. aeruginosa ATCC 27852 were used as quality control strains ${ }^{[11]}$.

Isolates were identified as colonizing organisms when they are isolated from swabs with lack of clinical symptoms of infection (Munch et al., 2017) ${ }^{[12]}$.

\section{Statistical analysis}

Data were coded, validated and analyzed using SPSS PC+ version 13 software package. Frequency, percentage, arithmetic mean, median and mode were used to present the data. Chi square, student " $t$ " test, onesample Kolmogorv-Smirnov Z test was used as tests of significance at $5 \%$ level of significance. Histograms and bar charts were used to graphically present the data. Binary logistic multivariate analysis, adjusted Odds ratio (OR) and antecedent $95 \%$ confidence intervals (CI) were used to identify potential risk factors for bacterial colonization, as well as the presence of pathogenic bacteria on HCWs' mobile phones

\section{Results}

This cross-sectional study included 350 HCWs, of whom $38 \mathrm{HCWs}$ were from ElMabarra hospital, while the rest from Zagazig University Hospital, The HCWs were between 21 and 56 years with a median age of 31 years and the number of females was 274 ; $78.3 \%$.
The study included $256(73.1 \%)$ nurses, $88(25.1 \%)$ physicians and $6(1.7)$ technicians.

Of all physicians $50 \%$ were registrars, while $27.3 \%$ were senior registrars and $9.1 \%$ were resident and consultant (table 1).

The median number of years of experience was 11 years with a range of 1 to 32 years.

All participants had mobile phones, and they came to the work with their phones, of whom $90.6 \%$ had only one phone, and $9.4 \%$ had more than one.

Almost half of the participants used their phones 4 to 6 times during their work shift.

The majority $(64 \%)$ of participants used their phones for both calling and internet browsing. Although the majority (88.9\%)of HCWs think that mobile phones are dangerous tool in hospital , $60.9 \%$ of them usually keep phones in the uniform pocket . however ,85.1\% of HCWs clean their phones and $57.1 \%$ accept restriction of use of phones during work in hospitals (table 2).

It is noteworthy that the attitude of HCWs toward the cleaning methods of phones was variable.

In this study bacterial growth was observed in 162 (46.3) mobile phones.

The most common organism isolated was S.epidermidis $(72.8 \%)$, followed by $S$. aureus (16.7\%), Bacillus spp.(6.2\%), and E. coli ;(3.1\%).(table 4, figure 2$)$

Overall, There was statistically significant association between the culture results with HCWs acceptance to restrict mobile use inside hospitals $\left(\mathrm{p}=0.038^{*}\right)$, using phones inside toilets $\left(\mathrm{p}=0.038^{*}\right)$, and keeping phones in the uniform pocket $(\mathrm{p}=0.00) *$ (table 3 ).

All Gram positive organisms isolated were sensitive to vancomycin, while the other antimicrobial drugs showed marked variations in response to the microbial agents (table 5). Isolates were identified as colonizing organisms when they are isolated from swabs with lack of clinical symptoms of infection (Munch et al., 2017).

\section{Tables}


Table (1): sex distribution among the studied group $(\mathrm{N}=350)$

\begin{tabular}{|l|l|l|l|}
\hline \multirow{2}{*}{ Sex } & Male & N & \% \\
\cline { 2 - 4 } & Female & $\mathbf{7 6}$ & $\mathbf{2 1 . 7}$ \\
\cline { 2 - 4 } & Total & $\mathbf{2 7 4}$ & $\mathbf{7 8 . 3}$ \\
\hline
\end{tabular}

Table (2): The occupation distribution among the studied group

\begin{tabular}{|l|l|l|l|}
\hline \multirow{3}{*}{ Job } & & $\mathrm{N}$ & $\%$ \\
\cline { 2 - 4 } & Doctor & $\mathbf{8 8}$ & $\mathbf{2 5 . 1}$ \\
\cline { 2 - 4 } & Nurse & $\mathbf{2 5 6}$ & $\mathbf{7 3 . 1}$ \\
\hline Technician & $\mathbf{6}$ & $\mathbf{1 . 7}$ \\
\cline { 2 - 4 } & Total & $\mathbf{3 5 0}$ & $\mathbf{1 0 0 . 0}$ \\
\hline
\end{tabular}

Table (3): The number and percentage of physicians according to their work position in the study

\begin{tabular}{|l|l|l|l|}
\hline \multirow{2}{*}{$\begin{array}{l}\text { Position } \\
\text { (dgree) }\end{array}$} & Med officer & N & \% \\
& Resident & $\mathbf{4}$ & $\mathbf{4 . 5}$ \\
& Registrar & $\mathbf{8}$ & $\mathbf{9 . 1}$ \\
\cline { 2 - 4 } & Sen. Registrar & $\mathbf{4 4}$ & $\mathbf{5 0 . 0}$ \\
\cline { 2 - 4 } & Consultant & $\mathbf{2 4}$ & $\mathbf{2 7 . 3}$ \\
\cline { 2 - 4 } & Total & $\mathbf{8}$ & $\mathbf{9 . 1}$ \\
\hline
\end{tabular}

Table (4): Number of mobile phones owend by HCWs:

\begin{tabular}{|l|l|l|l|}
\hline \multirow{2}{*}{ Mobile number } & One mobile & N & $\%$ \\
\cline { 2 - 4 } & More than one & 317 & 90.6 \\
\cline { 2 - 4 } & Total & 350 & $\mathbf{9 . 4}$ \\
\hline
\end{tabular}


Table (5): Attidude of HCWs toward use of mobile phones in hospitals:

\begin{tabular}{|c|c|c|c|}
\hline \multicolumn{2}{|l|}{ Questioner items } & \multirow{2}{*}{$\begin{array}{l}\text { N } \\
137\end{array}$} & \multirow{2}{*}{$\begin{array}{l}\% \\
39.1\end{array}$} \\
\hline Where do you Keep your & In clothes pocket & & \\
\hline hospital? & In uniform pocket & 213 & 60.9 \\
\hline \multirow[t]{2}{*}{ Do you use mobile in toilet? } & Yes & 48 & 13.7 \\
\hline & No & 302 & 86.3 \\
\hline \multirow{2}{*}{$\begin{array}{l}\text { Do you Accept restriction of } \\
\text { use mobile during work? }\end{array}$} & Yes & 200 & 57.1 \\
\hline & No & 150 & 42.9 \\
\hline \multirow{2}{*}{$\begin{array}{l}\text { Do you think mobile can be } \\
\text { harmful? }\end{array}$} & Yes & 311 & 88.9 \\
\hline & No & 39 & 11.1 \\
\hline \multirow{2}{*}{$\begin{array}{l}\text { Do you Clean your mobile } \\
\text { phones? }\end{array}$} & Yes & 298 & 85.1 \\
\hline & No or not regular & 52 & 14.9 \\
\hline \multirow{5}{*}{$\begin{array}{l}\text { How regular you clean your } \\
\text { mobile phone? }\end{array}$} & Daily & 45 & 12.9 \\
\hline & Day after day & 177 & 50.6 \\
\hline & Weekly & 61 & 17.4 \\
\hline & Monthly & 15 & 4.3 \\
\hline & Not regular & 52 & 14.9 \\
\hline \multirow{3}{*}{$\begin{array}{l}\text { How do you clean your } \\
\text { mobilet? }\end{array}$} & Alcohol & 122 & 34.9 \\
\hline & Wet cloth & 121 & 34.6 \\
\hline & Dry cloth & 107 & 30.6 \\
\hline \multirow{3}{*}{$\begin{array}{l}\text { How many times you clean } \\
\text { your hand? }\end{array}$} & $0-3$ & 54 & 15.4 \\
\hline & $4-6$ & 193 & 55.1 \\
\hline & $7-9$ & 103 & 29.4 \\
\hline \multirow[t]{4}{*}{ How you clean your Hand? } & Water \& soap & 101 & 28.9 \\
\hline & Alcohol hand rub & 181 & 51.7 \\
\hline & Both & 68 & 19.4 \\
\hline & Total & 350 & 100.0 \\
\hline
\end{tabular}


Table (6): The relationship of HCWs attitude toward using mobile phones and bacterial culture results

\begin{tabular}{|c|c|c|c|c|c|c|c|}
\hline & \multicolumn{2}{|c|}{ Culture } & \multirow[t]{2}{*}{ Total } & \multirow[t]{2}{*}{$\mathbf{X}^{2}$} & \multirow[t]{2}{*}{$\mathbf{P}$} \\
\hline & & & $-\mathrm{VE}$ & $+\mathrm{VE}$ & & & \\
\hline \multirow[t]{4}{*}{ Sex } & \multirow[t]{2}{*}{ Male } & $\mathrm{N}$ & 41 & 35 & 76 & \multirow[t]{4}{*}{0.002} & \multirow[t]{4}{*}{0.96} \\
\hline & & $\%$ & $21.8 \%$ & $21.6 \%$ & $21.7 \%$ & & \\
\hline & \multirow[t]{2}{*}{ Female } & $\mathrm{N}$ & 147 & 127 & 274 & & \\
\hline & & $\%$ & $78.2 \%$ & $78.4 \%$ & $78.3 \%$ & & \\
\hline \multirow[t]{6}{*}{ Job } & \multirow[t]{2}{*}{ Doctor } & $\mathrm{N}$ & 45 & 43 & 88 & \multirow[t]{6}{*}{1.42} & \multirow[t]{6}{*}{0.48} \\
\hline & & $\%$ & $23.9 \%$ & $26.5 \%$ & $25.1 \%$ & & \\
\hline & \multirow[t]{2}{*}{ Nurse } & $\mathrm{N}$ & 141 & 115 & 256 & & \\
\hline & & $\%$ & $75.0 \%$ & $71.0 \%$ & $73.1 \%$ & & \\
\hline & \multirow[t]{2}{*}{ Technician } & $\mathrm{N}$ & 2 & 4 & 6 & & \\
\hline & & $\%$ & $1.1 \%$ & $2.5 \%$ & $1.7 \%$ & & \\
\hline \multirow[t]{4}{*}{ Mobile $\mathrm{n}$} & \multirow[t]{2}{*}{ One } & $\mathrm{N}$ & 171 & 146 & 317 & \multirow[t]{4}{*}{0.071} & \multirow[t]{4}{*}{0.79} \\
\hline & & $\%$ & $91.0 \%$ & $90.1 \%$ & $90.6 \%$ & & \\
\hline & \multirow[t]{2}{*}{ More } & $\mathrm{N}$ & 17 & 16 & 33 & & \\
\hline & & $\%$ & $9.0 \%$ & $9.9 \%$ & $9.4 \%$ & & \\
\hline \multirow[t]{6}{*}{ Reason } & \multirow[t]{2}{*}{ Call } & $\mathrm{N}$ & 42 & 41 & 83 & 2.69 & 0.26 \\
\hline & & $\%$ & $22.3 \%$ & $25.3 \%$ & $23.7 \%$ & & \\
\hline & Internet & $\mathrm{N}$ & 19 & 24 & 43 & & \\
\hline & & $\%$ & $10.1 \%$ & $14.8 \%$ & $12.3 \%$ & & \\
\hline & Both & $\mathrm{N}$ & 127 & 97 & 224 & & \\
\hline & & $\%$ & $67.6 \%$ & $59.9 \%$ & $64.0 \%$ & & \\
\hline Keep & Cloth & $\mathrm{N}$ & 97 & 40 & 137 & 26.4 & $0.00 * *$ \\
\hline & & $\%$ & $51.5 \%$ & $24.7 \%$ & $39.1 \%$ & & \\
\hline & Uniform & $\mathrm{N}$ & 91 & 122 & 213 & & \\
\hline & & $\%$ & $48.5 \%$ & $75.3 \%$ & $60.9 \%$ & & \\
\hline Mobile toilet & Yes & $\mathrm{N}$ & 19 & 29 & 48 & 4.46 & $0.038 *$ \\
\hline & & $\%$ & $10.1 \%$ & $17.9 \%$ & $13.7 \%$ & & \\
\hline & No & $\mathrm{N}$ & 169 & 133 & 302 & & \\
\hline & & $\%$ & $89.9 \%$ & $82.1 \%$ & $86.3 \%$ & & \\
\hline Restriction & Yes & $\mathrm{N}$ & 117 & 83 & 200 & 4.29 & $0.038 *$ \\
\hline mobile & & $\%$ & $62.2 \%$ & $51.2 \%$ & $57.1 \%$ & & \\
\hline & No & $\mathrm{N}$ & 71 & 79 & 150 & & \\
\hline & & $\%$ & $37.8 \%$ & $48.8 \%$ & $42.9 \%$ & & \\
\hline Mobile harm & Yes & $\mathrm{N}$ & 169 & 142 & 311 & 0.44 & 0.507 \\
\hline & & $\%$ & $89.9 \%$ & $87.7 \%$ & $88.9 \%$ & & \\
\hline & No & $\mathrm{N}$ & 19 & 20 & 39 & & \\
\hline & & $\%$ & $10.1 \%$ & $12.3 \%$ & $11.1 \%$ & & \\
\hline Clean & Yes & $\mathrm{N}$ & 178 & 116 & 298 & 30.3 & $0.00 * *$ \\
\hline & & $\%$ & $94.6 \%$ & $71.6 \%$ & $85.1 \%$ & & \\
\hline & No & $\mathrm{N}$ & 10 & 42 & 52 & & \\
\hline & & $\%$ & $5.4 \%$ & $28.4 \%$ & $14.9 \%$ & & \\
\hline How c lean & Alcohol & $\mathrm{N}$ & 62 & 60 & 122 & 1.21 & 0.54 \\
\hline & & $\%$ & $33.0 \%$ & $37.0 \%$ & $34.9 \%$ & & \\
\hline & Wet & $\mathrm{N}$ & 64 & 57 & 121 & & \\
\hline
\end{tabular}




\begin{tabular}{|c|c|c|c|c|c|c|c|}
\hline & \multirow{3}{*}{ Dry } & $\%$ & $34.0 \%$ & $35.2 \%$ & $34.6 \%$ & & \\
\hline & & $\mathrm{N}$ & 62 & 45 & 107 & & \\
\hline & & $\%$ & $33.0 \%$ & $27.8 \%$ & $30.6 \%$ & & \\
\hline \multirow{6}{*}{$\begin{array}{l}\text { Hand } \\
\text { method }\end{array}$} & \multirow{2}{*}{$\begin{array}{l}\text { Water \& } \\
\text { soap }\end{array}$} & $\mathrm{N}$ & 47 & 54 & 101 & \multirow[t]{6}{*}{3.12} & \multirow[t]{6}{*}{0.21} \\
\hline & & $\%$ & $25.0 \%$ & $33.3 \%$ & $28.9 \%$ & & \\
\hline & \multirow[t]{2}{*}{ Alcohol rub } & $\mathrm{N}$ & 101 & 80 & 181 & & \\
\hline & & $\%$ & $53.7 \%$ & $49.4 \%$ & $51.7 \%$ & & \\
\hline & \multirow[t]{2}{*}{ Both } & $\mathrm{N}$ & 40 & 28 & 68 & & \\
\hline & & $\%$ & $21.3 \%$ & $17.3 \%$ & $19.4 \%$ & & \\
\hline \multirow{2}{*}{\multicolumn{2}{|c|}{ Total }} & $\mathrm{N}$ & 188 & 162 & 350 & & \\
\hline & & $\%$ & $100.0 \%$ & $100.0 \%$ & $100.0 \%$ & & \\
\hline
\end{tabular}

Table (7): Number and percentage of isolated bacteria spp. Sensitive / resistant to selected antimicrobial agents

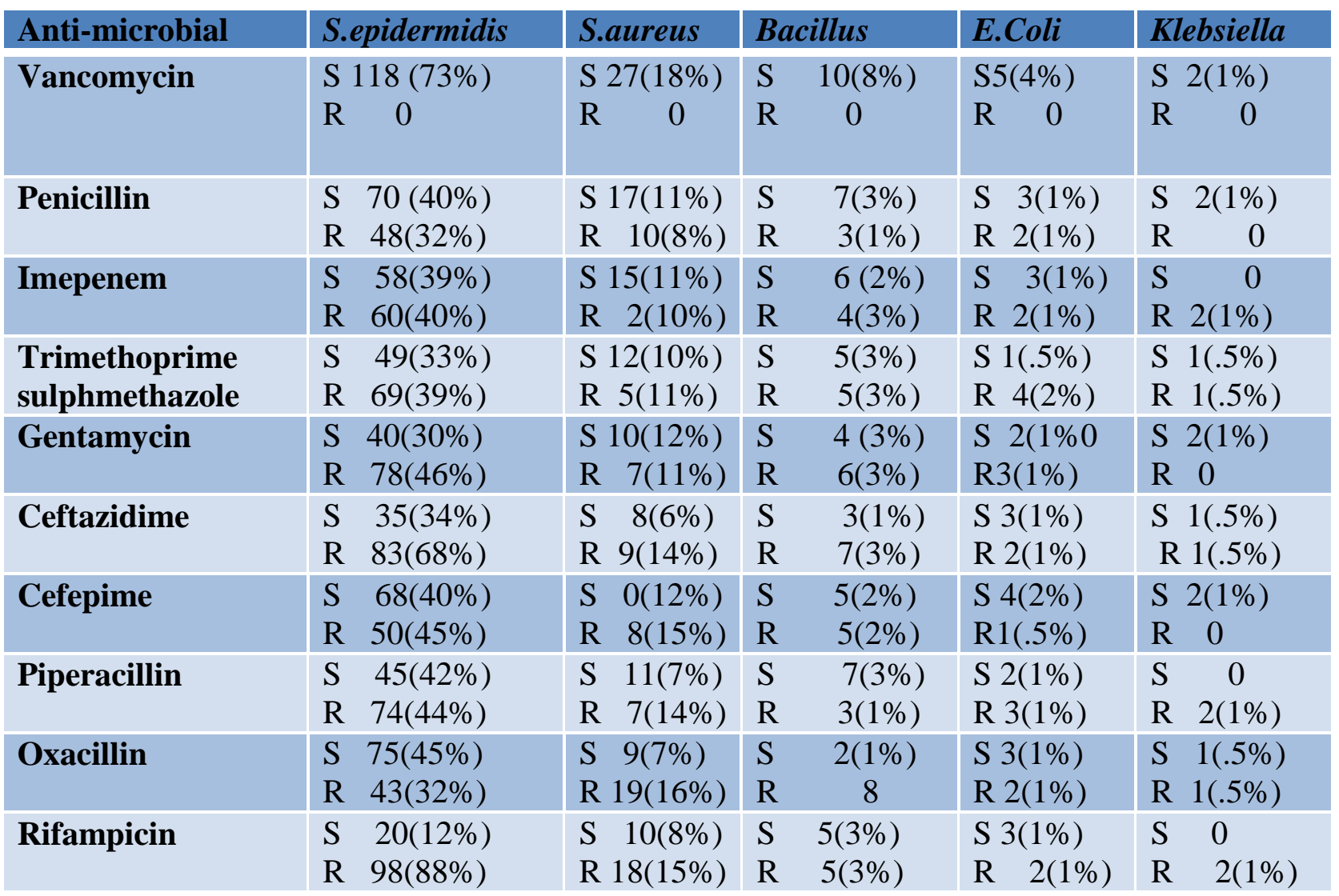




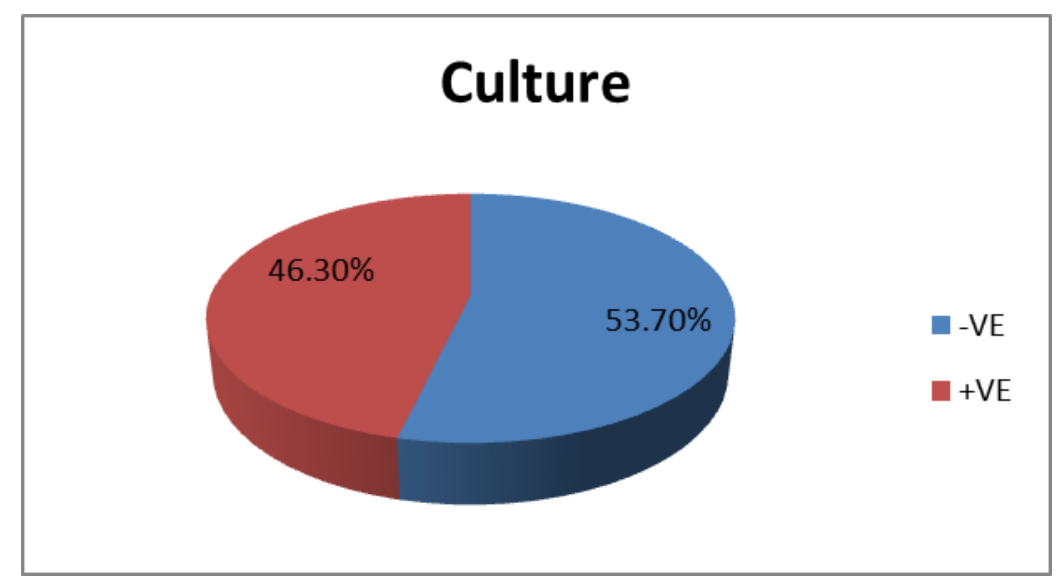

Figure (1): The percentage of culture results of samples from HCWs mobile phones:

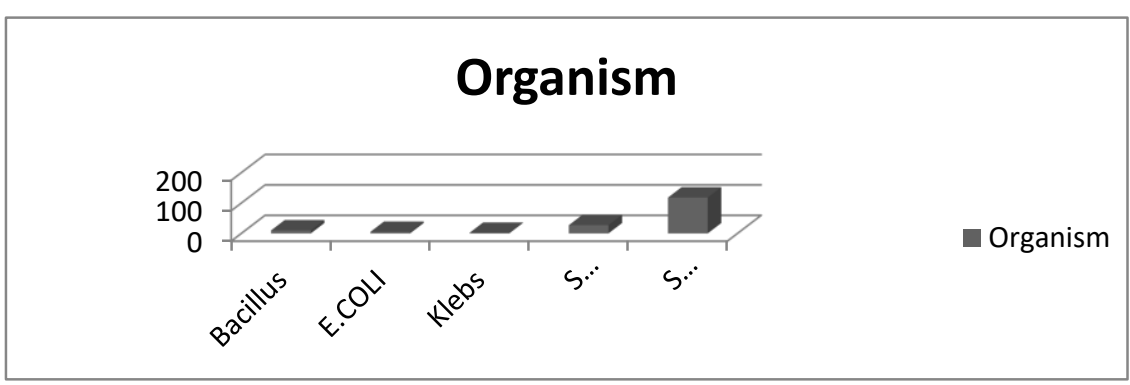

Figure (2): The number and percentage of isolated organisms from mobile phones of the studied group:

\section{DISCUSSION}

. In our study, approximately $46.3 \%$ of mobile phones were contaminated. This is higher than that reported from Saudi Arabia, where $43.6 \%$ of clinicians' mobile phones in wards, emergency rooms, out-patient departments, and operating rooms were contaminated; and in India, where of clinicians' mobile phones in different wards were contaminated. On the other hand, the prevalence of contamination of clinicians' mobile phones in our setting was lower than that reported from other studies in Turkey, where $94.5 \%$ of clinicians' mobile phones in operating rooms and ICUs were contaminated, and $97.8 \%$ of clinicians' mobile phones in another Turkish study ${ }^{[12]}$.

Higher estimates of the contamination of clinicians' mobile phones have also been reported from UK $(96.2 \%$ of mobile phones of all physicians), Austria (95\% of mobile phones of anes-thetists), Saudi Arabia (96.5 $\%$ of mobile phones of clinicians in ICU) and
Nigeria $(94.6 \%$ of mobile phones of health care workers in a hospital) ${ }^{[13]}$.

In another study, 40 mobile phones from 4 different departments of a health care setting were screened for the presence of bacterial contamination. All of them were having one or more organism. All 100 mobile phones sampled were contaminated with varied numbers of bacteria. 98\% culture-positive specimens were isolated from examined mobile phones of the HCWs. $83 \%$ of screened mobile phones of the HCWs showed bacterial contamination $^{[14]}$.

The direct comparison between the findings of different studies is hindered by various factors, including targeting different hospital wards and different laboratory procedures. The contamination rate of clinicians' mobile phones in Zagazig hospitals seems to be within the range that was reported in other literature. In terms of self-reported mobile phone hygiene practices, $15 \%$ of the participants have never disinfected their 
mobile phones. This is lower than that reported from Saudi Arabia, where $76.0 \%$ of clinicians have never disinfected their mobile phones; and in a surgical setting in Northern Ireland, where only $37 \%$ of health- care workers admitted cleaning their mobile phone regularly ${ }^{[15]}$.

Other studies have investigated factors related to mobile phone contamination and included gender of the clinician, number of times the mobile phone is used at work, type of phone, and medical specialty of the clinician; but none of these factors was found to be significant ${ }^{[15]}$.

Variable contamination rates of cell phones were reported in different countries: USA: $20 \%$, UK: $55 \%$, Nigeria and Ethiopia: $62 \%$ each, India: 72.5\%, Australia: $74 \%$, KSA: $84 \%$, Turkey: 94.5\%, Austria: 95\% and Cairo: $96.5 \%$. This variation may be due to differences in mobile phone handling and cleaning and in hand washing practice ${ }^{[16]}$.

In our study, we investigated the opinion of HCWs about the potential role of mobile phones in spreading nosocomial infections. Approximately, $89 \%$ of HCWs thought that mobile phones can play a role in spreading infections in healthcare settings. However, $57 \%$ of HCWs accepted banning the use of mobile phones in their units. This is slightly lower than what has been reported in a study from UK, in which $78.0 \%$ of HCWs opposed banning the use of mobile phones in hospitals. While losing the momentum to ban mobile phones in ICUs and other clinical settings, it is sensible to increase the awareness about mobile phones disinfection rather than trying to forcefully ban using mobile phones in clinical settings ${ }^{[17]}$.

In the current study S.epidermidis was detected in $72.8 \%$ of the samples, followed by S.aureus (16.7\%), Bacillus (6,2\%), E.Coli (3.1\%), and klebsiella (1.2\%).

Our results were in agreement with the results found that S.epidermidis was the most common organism causing NI. However, the most frequently isolated organisms were CONS (23.4\%), Klebsiella spp. (22.1\%) and Enterobacter cloacae (20.8\%). In Bahrami Children Hospital in Tehran, Iran found that, the most common pathogenic organisms were
Enterobacter (27\%), Staphylococcus aurues (21\%), Klebsiella (18\%), E. coli (14\%), and Epidermis Staphylococcus (9\%). The hands of HCWs may not only transmit organisms but also become a reservoir for nosocomial organisms ${ }^{[18,19]}$.

MRSA was isolated from $53.3 \%$ of HCWs mobile phones. The isolated bacteria included Klebsiella pneumoniae (10\%), Citrobacter spp. (2\%), S. aureus (4\%), CoNS (15\%), Pseudomonas aeruginosa (4\%), Salmonella spp. (3\%), Shigella spp. (2\%), Proteus mirabilis (19\%), E. coli (8\%), Bacillus cereus (23\%), Streptococcus pneumoniae (10\%), Salmonella spp. (3\%) and Shigella spp. (2\%). The isolation of $S$. aureus was maximum in all the categories of HCWs (54\%), followed by micrococci (21\%), diphtheroids( $8 \%)$,enterococci(4\%),

Pseudomonas, Citrobacter and Bacillus spp. (3\% each), Acinetobacter, Enterobacter and Streptococcus viridans (2\% each). CoNS was the dominant organism (72\%) followed by Diphtheroids (22\%) and Aspergillus niger 2 $(6 \%)$. Out of the 50 samples from HCWs, 10 were contaminated with $S$. aureus, 4 CoNS, one E. coli and Pseudomonas spp. together. Of the $10 \mathrm{~S}$. aureus $40 \%$ were resistant to methicillin ${ }^{[20]}$.

CoNS was the most prevalent (69 \%) bacteria from mobile phones of volunteers in the community. $52 \%$ of the examined mobile phones of HCWs were contaminated by $S$. aureus. In this work, it has been noted that S.epidermidis was the most frequently encountered isolates.

This pathogen is of greater concern because of its virulence, its ability to cause a diverse array of life threatening infections, and its capacity to adapt to different environmental conditions. It is also a well known fact that Organisms like $S$. aureus resist dryness and thus can survive and multiply rapidly in warm environments like cell phones ${ }^{[21]}$.

Another study done by ${ }^{[22]}$ founded that Coagulase-negative Staphylococci were the most prevalent bacteria ( $80.6 \%$ ) isolated from mobile phones and this finding correlates well with the results of other researchers $(90.5 \%)$, (82\%), (48\%), (42.7\%), (40\%). 
$S$. aureus is one of the frequently isolated bacteria in hospital infection and in the same study was isolated from 202 (63.9\%) contaminated mobile phones out of which 16 (7.9\%) were MRSA. Among the contaminated hand samples $95(30.7 \%)$ isolates were $S$. aureus out of which $1(1.1 \%)$ isolate was $\operatorname{MRSA}^{[23]}$.

Isolation of MRSA was a cause of concern as these are epidemiologically important drug-resistant pathogens. Our finding is in agreement with the work of ${ }^{[21]}$ who reported $40 \%$ of the mobile phones at Mangalore hospital to be contaminated by $S$. aureus. Whereas from Nigeria reported that $17.14 \%$ to $25.71 \%$ of mobile phones in different wards were contaminated by $S$. aureus. The MRSA carriage status however is much higher in Indian hospitals than those reported from western countries which range from 0 to $1.9 \%$. Comparatively poor hygiene and hand washing practices followed by $\mathrm{HCW}$ in India might be the contributory factor ${ }^{[24]}$.

It's a well-established fact that all these organisms are agents of nosocomial infection. Pseudomonas aeruginosa has been reported in the United States by the Centre of disease control and prevention to be the most isolated nosocomial pathogen accounting for $10.1 \%$ of all HAI, The horizontal spread of resistance factors into environmental gram negative bacilli (GNB) has seen the emergence of MDR ,Acinetobacter, Pseudomonas, and coliforms, wherever looked for, even in skin carriage strains ${ }^{[25]}$.

Regularly, this finding substantiates the high rate of contamination and its transmission between hands and mobile phones in our study.

The present results highlighted that $85 \%$ of the participants cleaned their mobile phones frequently compared to $15 \%$ who claimed they never cleaned their phones. The rates of frequent cleaning of HCWs, mobile phones recorded worldwide in previous studies varied from $10.5 \%$ in Turkey to $31 \%$ in Australia. In the gulf zone, $66.5 \%$ of HCWs in Kuwait and $76 \%$ of those in KSA stated they never cleaned their mobile phones ${ }^{[26]}$.

A practice guideline was issued by the community and Hospital Infection Control
Association (CHICA, Canada) to address the issues of electronic devices in health care settings. Some of their recommendations include that hand hygiene should be performed between patient $\backslash$ contact and before and after accessing a device, manufacturer's guidelines for use, cleaning/disinfection and maintenance should be reviewed to ensure that these guidelines meet the standards for cleaning and low-level disinfection that are necessary for exposure to multi drug resistant organisms .

The most successful interventions to reduce hospital acquired infections were sustained hand hygiene promotion and local infection surveillance approach.

\section{CONCLUSION}

The prevalence of clinicians' mobile phones that are contaminated by various microorganism in the ICUs, PICUs, and NICUs was high. Although most microorganisms can be considered nonpathogenic in normal circumstances, these are potentially harmful in ICU and NCU settings, where patients are extremely vulnerable to infections. Some mobile phones harbored extremely harmful bacteria, such as MRSA or Gram-negative organisms. Our findings highlight the need for a more comprehensive approach to reduce nosocomial infections, which in addition to promoting hand hygiene also focus on cleanliness of mobile phones and other objects that clinicians may carry. Only minority of clinicians have ever disinfected their mobile phones, which is not an optimal practice and highlights the need to increase the awareness about mobile phones disinfection among clinicians, given that banning mobile phones in ICU settings is losing momentum. Finally, further research is needed in order to provide evidence that better mobile phone hygiene will lead to a reduction in HAIs.

\section{Declaration of interest :}

The authors report no conflicts of interest. The authors alone are responsible for the content and writing of the paper.

Funding information : None declared REFERENCES

1. Denise Von Dollinger BritoI; Cristiane Silveira de BritoI; Daiane Silva ResendeI; 
Jacqueline Moreira do ÓI; Vânia Olivetti Steffen AbdallahII et al (2010). Nosocomial infections in a Brazilian neonatal intensive care unit. Rev Soc Bras Med Trop; 43(6): 633-637.

2. Horn TC, Gaynes RP, Martone WJ, Jarvis WR, Emori TG. CDC definitions of nosocomial surgical site infections, 1992: a modification of CDC definitions of surgical wound infections. Infect Control Hosp Epidemiol 1992; 13(10): 606-8.

3. Salamati P, Rahbarimanesh A.A, Yunesian M and Nasari M (2006): Neonatal nosocomial infection in Bahrami children hospital. Indian J Pediatr; 73: 197-200.

4. Mahfouz A.A., Al Azraqi T.A., Abbag F.I., Al Gamal M.N., Seef S. (2010):Nosocomial infections in a neonatal intensive care unit in south-western Saudi Arabia. EMHJ; 16(1): 40-44.

5. Nagata E, Brito A.S, and Mastuo T (2009): Nosocomial infections in neonatal intensive care units: incidence and risk factors. AM J infect control; 37: 28-34.

6. Abd El-Wahab1, M.A.A., Naeem, A.M., ELMashad, A.E.M., and Sallam, N.R.M.(2016): Antibiotic Associated Diarrhea and Incidence of Clostridium difficile Infection and Colonization in Infants and Children in Tanta University Hospital, Egypt Int .J. Curr. Microbiol. App. Sci , 5(1): 575-585.

7. Dutto M., and Bertero M. (2011): Cutaneous superficial myiasis: report of a rare nosocomial parasitic disease caused by Sarcophaga spp. (Diptera, Sarcophagidae). Central European Journal of Public Health 19: 232-234.

8. Eliewa ME (2007): Nosocomial infections in the neonatal intensive care unit of obstetrics and gynecology Hospital, Ain Shams University: incidence and risk factors. Thesis submitted for fulfillment of master degree in pediatrics, supervised by Prof. Dr. Mamdouh Abdulmaksoud, Dr. Maha A. Awadalla and Dr. Hala M. Hafez. Ain Shams University.

9. Murray, P.R., Baron, E.J., P faller, M.A., et al. (2003): Manual of Clinical Microbiology Handbook. Washington, D.C.

10.Clinical and Laboratory Standards Institute. Performance standards for antimicrobial susceptibility testing; Twenty-fourth informational supplement, M100S24.Wayne,PA:CLSI;2014

11.https://www.evidencepartners.com/resources/ forest-plot generator/\#forest_plot_11_graph_edit_setting
$\mathrm{S}$

12.Munch J, Hagen R, Muller M (2017). Colonization with multidrug resistant bacteria on the deficiency of local decolonization procedures. Euro J Clin Microbial;7(2): 99111.

13.Clark R, Powers R, White R, Barry Bloom MD, Pablo Sanchez MD, Daniel K Benjamin,et al (2004): Nosocomial infection in the NICU: a medical complication or unavoidable problem? J Perinatol; 24: 382388.

14.Hidron, A.I., Edwards, J.R., Patel, J., Teresa C, Dawn M. Sievert, Daniel A. Pollock et al.(2008): NHSN annual update: antimicrobial-resistant pathogens associated with healthcare-associated infections: annual summary of data reported to the National Healthcare Safety Network at the Centers for Disease Control and Prevention, 20062007. Infect Control Hosp Epidemiol, 29:996-1011

15.Ibrahim YS, Said AM and Hamdy GK (2011): Assessment of infection control practices in a neonatal intensive care unit (NICU). Egypt J Comm Med; 29(4): 27-45.

16.Bischoff WE, Reynolds TM, Sessler CN, Edmond MB, Wenzel RP.(2000): Hand washing compliance by health care workers: The impact of introducing an accessible, alcohol-based hand antiseptic. Arch Intern Med. 10; 160(7):1017-21.

17.Gaynes, R., and Edwards, J.R.(2005): Overview of nosocomial infections caused by gram-negative bacilli. Clin Infect Dis, 41:848-854.

18.Głowny Inspektorat Sanitarny (2011): Stan Sanitarny Kraju w roku 2010. Głowny Inspektorat Sanitarny. Warszawa

19.Assiri, A.M., Choudhry, A., Alsaleh, S.S., Alanazi, K.H., Alsaleh, S.S.(2014): Evaluation of Infection Prevention and Control Programmes (IPC), and Assessment Tools for IPC-Programmes at MOH-Health Facilities in Saudi Arabia. Open Journal of Nursing, 4, 483-492

20.Blachere, F. M., Lindsley, W. G., Pearce, T. A, Melanie A. Fisher, Rashida Khakoo, Stephen M. Davis et al.,(2009): "Measurement of airborne influenza virus in a hospital emergency department," Clinical Infectious Diseases, vol. 48, no. 4, pp. 438440.

21.Langely J \& Bradley J: Defining Pneumonia in Critically ill infant and child; Pediatric Critical Care Medicine; 6;3 (2005). 
22.Macinga DR, Sattar SA, Jaykus L-A, Arbogast JW. Improved Inactivation of Nonenveloped Enteric Viruses and Their Surrogates by a Novel AlcoholBased Hand Sanitizer. Appl Environ Microbiol. 2008;74(16):5047-52.

23.Nicolay CR. Hand hygiene: an evidencebased review for surgeons. Int J Surg. 2006;4(1):53-65.

24.Omar MM (2001): Nosocomial infections in Kasr El Aini neonatal intensive care unit (NICU) as a university hospital. Thesis submitted for partial fulfillment of master degree in pediatrics, supervised by Prof. Dr. Eman Seaud, Prof. Dr. Maha Ghobashi and Dr. Iman F. Iskander. Cairo University.
25.Picheansathian W. A systematic review on the effectiveness of alcohol-based solutions for hand hygiene. Int $\mathbf{J}$ Nurs Pract. 2004;10(1):3-9.

26.Richards M, Edwards J, Culver D, Gaynes R: Nosocomial Infections in Pediatric Intensive Care Units in the United States, PEDIATRICS Vol. 103 No. 4 , p. e39, (1999).

27.Saiman, L., Ludington, E., Pfaller, M., Rangel-Frausto, S., Wiblin, R.T., Dawson, J, et al.(2000): Risk factors for candidemia in Neonatal Intensive Care Unit patients. The National Epidemiology of Mycosis Survey study group. Pediatr Infect Dis J. 19:319-24.

To Cite This Article: El-Rahman TA, Amer OT, Morad AM, Mohamed ME. Bacterial Contamination of Healthcare Workers' Mobile Phones in Pediatric and Neonatal Departments of Two Hospitals in Zagazig City.Zumj May. 2020(26) No.3,384-396; doi: 10.21608/zumj.2019.13773.1263. 